\title{
Pilar Godayol. 2016. Tres escriptores censurades. Simone de Beauvoir, Betty Friedan \& Mary McCarthy. Lleida: Punctum, 205 p.
}

TERESA IRIBARREN

Universitat Oberta de Catalunya (Espanya) · orcid.org/0000-0002-5052-7770

http://dx.doi.org/10.7238/fit.voi4.3063

Pilar Godayol és professora del Departament de Traducció, Interpretació i Llengües Aplicades de la Universitat de Vic, i membre del Centre d'Estudis Interdisciplinaris de Gènere - en el qual s'aixopluga la Càtedra UNESCO Dones, desenvolupament i cultures-, adscrit a la mateixa institució. En lògica correlació, el seu àmbit de recerca se situa a cavall entre la disciplina de la traducció literària i els estudis sobre obra d'escriptores. La intensa tasca de recerca que Godayol ha desplegat els darrers anys ha contribuït a engruixir els estudis sobre història de la traducció a Catalunya. Alguns dels seus treballs més destacats els ha publicat conjuntament amb Montserrat Bacardí, professora de la Universitat Autònoma de Barcelona: Una impossibilitat possible. Trenta anys de traducció als Països Catalans (1975-2009) (2009), el Diccionari de la Traducció Catalana (2011, Premi Crítica Serra d'Or de Recerca en Humanitats 2012), i Les traductores i la tradició. 20 pròlegs del segle $x x$ (2013). Aquesta darrera obra s'inclou en la collecció Visions de l'editorial lleidatana Punctum - una collecció del Grup d'Estudis de la Traducció Catalana Contemporània de la UAB, que dirigeix Bacardí-, consagrada a difondre documents i estudis sobre traducció catalana contemporània. En aquesta mateixa collecció ha aparegut el 2016 el darrer llibre signat per Godayol, Tres escriptores censurades. Simone de Beauvoir, Betty Friedan $\mathcal{E}$ Mary McCarthy. Ara com ara, ambdós títols són els únics de la collecció dedicats a escriptores i traductores.

Tres escriptores censurades. Simone de Beauvoir, Betty Friedan \& Mary McCarthy és un estudi que se situa en el punt d'intersecció dels dos principals interessos investigadors de Godayol. Concebut a manera de tríptic, articula tres relats sobre les vicissituds que van experimentar dos assaigs i una novella - un text francès i dos estatunidencs - en la seva translació al sistema literari català i, de manera més tangencial, al castellà. Les rúbriques dels capítols, que s'ordenen d'acord amb l'any d'aparició de 
les obres originals, són: «Simone de Beauvoir i Le deuxième sexe (1949)», «Betty Friedan i The feminine mystique (1963)» i «Mary McCarthy i The group (1963)». En tots ells el focus se situa en els protocols de la censura franquista a què van ser sotmesos aquests textos emblemàtics del feminisme del segle $\mathrm{xx}$, les conseqüències editorials que van suposar els dictàmens -emesos en tots els casos per homes, com el reputat acadèmic pertanyent a l'ordre agustiniana Saturnino Álvarez Turienzo-, la fortuna que van tenir en l'aterratge a l'Estat espanyol i, en darrer terme, el seu efecte fecundador en escriptores tant en expressió castellana com, especialment, catalana. I és que el llibre té raó de ser, sobretot, per la gran troballa que va fer Godayol a l'Archivo General de la Administración d'Alcalá de Henares: els expedients de censura de les traduccions d'unes obres que xocaven frontalment amb l'ideari franquista quant a la condició femenina, especialment controvertides pel fet de plantejar qüestions tabú com ara la llibertat sexual, l'anticoncepció o la masturbació femenina. Aquesta documentació, informes i cartes dels editors exhumats del Fondo Ministerio de Información y Turismo (Ministerio de Educación, Cultura y Deporte), és d'un valor històric i cultural de primer ordre. Ben mirat, expliquen en clau sinecdòquica per què el feminisme es desenrotllà a Espanya, i particularment a Catalunya, molts anys més tard i de manera més diluïda que en d'altres països occidentals. L'indiscutible interès historicocultural dels documents legitima Godayol a incloure'n la reproducció en les darreres cinquanta pàgines del llibre. Posar-los a l'abast del lector és una operació de gran eficàcia instructiva, perquè contribueix a donar a conèixer el capciós mecanisme de repressió cultural de l'administració franquista que va ser la censura a partir del cas ben illustratiu d'unes obres que vehiculaven un ideari progressista. A més, permet a la investigadora desenrotllar la crònica dels entrebancs amb què van topar cadascuna de les obres amb el benentès que el lector pot consultar per compte propi el material d'arxiu i analitzar amb precisió els engranatges administratius, les estratègies de coerció (prohibicions, amputacions, dilacions) i la retòrica de l'aparell censor.

La riquesa documental dels expedients de la censura contrasta amb la migradesa de la documentació existent en relació amb la circulació pública dels tres textos feministes, com descobrirà el lector atent a me- 
sura que avança la lectura. Segons Godayol, només van tenir una ressenya tant el Premi Pulitzer de 1964, La mística de la feminitat (1965), en traducció de Jordi Solé Tura, com El segon sexe (1968; això és, dinou anys més tard que l'aparició de l'original francès, per bé que havia circulat clandestinament per Espanya la versió argentina de 1954), en traducció d'Hermínia Grau de Duran i Carme Vilaginés, i pròleg de Maria Aurèlia Capmany, la gran ambaixadora de la francesa en l'àmbit català. La novella $E l$ grup, al seu torn, ni tan sols va ser traduïda al català, atesa la denegació dictada pels censors - la traducció castellana, denegada el 1965, no va ser autoritzada fins després de la mort del dictador, el 1976. D’una banda, doncs, la migradesa de la recepció crítica en el cas de Friedan i inexistent en el cas de McCarthy no permet bastir un discurs diacrònic a partir de l'impacte periodístic o acadèmic que tingueren a curt termini els títols. D’altra banda, la inexistència de la traducció de la transgressora novella de McCarthy impossibilita construir un discurs sincrònic de naturalesa lingüística de la tríada, que hauria permès provar si els traductors, per exemple, es van autocensurar.

Davant d'aquest desequilibri de les fonts documentals, en bona mesura fruit de la política repressora del règim, Godayol desplega la següent estratègia: construir «una narració de tres viatges» (11), segons que exposa en la breu presentació que encapçala el llibre. En efecte, atesa la impossibilitat de bastir un volum globalment concebut dins dels paràmetres disciplinaris de l'estètica de la recepció, ni tampoc de l'anàlisi textual comparativa de les obres traduïdes, Godayol opta per fer seva l'estratègia discursiva de la professora de literatura comparada de la Universitat de Nova York, Emily Apter; això és, bastir una biografia de les traduccions. I ho fa amb la mirada entomològica proposada per Jeremy Munday, la «microhistòria», en intersecció amb els plantejaments d'André Lefevere, que convida a contemplar la traducció depassant el terreny lingüístic i atenent totes les seves dimensions culturals. D’aquesta manera, Godayol desplega tres relats de naturalesa tentacular, amb llicències creatives pròpies del gènere biogràfic, i no sempre seguint una estricta evolució històrica, a l'entorn dels textos i del tarannà de Beauvoir, Friedan i McCarthy. La informació que hi aporta comprèn des d'episodis personals de les autores (relacions amoroses, viatges, breus estades a l'Es- 
tat espanyol) i relacions intellectuals (els binomis Beauvoir-Sartre, Friedan-Beauvoir, McCarthy-Hannah Arendt, les trobades entre Castellet i McCarthy), la sumària trajectòria cultural i el breu retrat de les figures implicades en la mediació literària — salpebrada amb amenes anècdotes personals-, fins a argúcies editorials i episodis dels cercles culturals de Barcelona i de Madrid tenallats pel franquisme. El fil dels tres relats, que geogràficament condueix el lector per escenaris parisencs, estatunidencs, madrilenys i barcelonins, permet conèixer diferents facetes de les tres autores i descobrir el paper que van tenir en la difusió de llur obra una àmplia constellació de figures del món cultural espanyol i català. Entre els catalans que bregaren per introduir en el context franquista les renovadores idees del feminisme i divulgar l'obra de les autores destaquen Josep Maria Castellet, Ramon Bastardes, Max Cahner, Jordi Solé Tura, Josep A. Baixeras, Joan Oliver, entre d'altres, i molt especialment Maria Aurèlia Campany, l'ascendent de la qual fou fonamental en el moviment feminista català.

Tres escriptores censurades. Simone de Beauvoir, Betty Friedan \& Mary McCarthy aconsegueix diversos objectius. En primer lloc, constatar l'eficàcia de l'aparell de censura franquista a l'hora d'impedir o, si més no, dificultar la penetració del feminisme a l'Estat espanyol. En segon lloc, demostrar que els textos fonamentals del feminisme català que emergeix als anys seixanta van ser la traducció de La mística de la feminitat, l'assaig La dona a Catalunya (1966) de Maria Aurèlia Capmany —clarament deutor de Beauvoir-, i la traducció d'El segon sexe. La influència d'aquestes tres obres, afirma Godayol, és encara perdura avui, després d'haver influit autores com ara Montserrat Roig, Helena Valentí i Maria Mercè Marçal. I en darrera instància, en brindar una visió panoràmica de l'obra de tres figures rellevants del feminisme de la segona meitat del segle xx i dels seus mediadors en l'àmbit espanyol i català, contribueix a conèixer millor fins a quin punt va ser dificultós començar a subvertir les dinàmiques del poder patriarcal que han governat els sistemes literaris. Una complexa i costeruda operació — protagonitzada per una cohort molt limitada d'escriptores, val a dir-ho- que el franquisme, com Godayol demostra, va condicionar i endarrerir notablement quant al sistema literari català. 